\title{
SWITCHED-BEAM ARRAY ANTENNA AT 28 GHZ FOR 5G WIRELESS SYSTEM BASED ON BUTLER MATRIX BEAMFORMING NETWORK
}

\author{
S. I. Orakwue ${ }^{1, *}$ and R. Ngah² \\ 1, DePT. OF Electrical Electronic Engineering, University of PORT-HARCOURT, Rivers State, NIGERIA. \\ 2, WireleSS Comm. Centre, UNIVERSITI TEKNOLOGI MALAYSIA (UTM), 81310 SKUDAI, JOHOR, MALAYSIA \\ E-mail addresses: ${ }^{1}$ stella.orakwue@uniport.edu.ng, ${ }^{2}$ razalingah@fke.utm.my
}

\begin{abstract}
This work presents a compact, switched-beam array antenna on $4 \times 4$ Butler Matrix (BM) beamforming network (BFN) at $28 \mathrm{GHz}$ for fifth generation (5G) wireless system. A single layer has been chosen to ensure low cost and ease fabrication. The four input ports of the designed antenna have the capability of producing four independent directional beam patterns at $13.8^{\circ},-43.5^{\circ}, 44^{\circ}$ and $-14^{\circ}$, when P1, P2, P3 and P4, respectively are excited. The radiation efficiency obtained from each of the four ports is well above $80 \%$ at the designated frequency. The peak antenna gain of $15.9 \mathrm{dBi}$ is obtained at port 1 and 4. The design is verified by measurement and all results have a good correlation with simulation.
\end{abstract}

Keywords: Array antenna, Butler matrix, millimetre wave, switched-beam antenna, 5G

\section{INTRODUCTION}

Fifth generation (5G) wireless system is expected to address the challenges of massive capacity and massive connectivity caused by the exponentially growing mobile traffic and the increasing machine type applications. To achieve this, recent researches had shown that millimetre wave band that offers large bandwidth is a feasible possibility for $5 G$ mobile communications systems $[1,2]$ to eliminate challenges of further improvement in spectral efficiency. In addition, Samsung in 2013 proposed smart antenna system (SAS) as a solution to combat attenuation and propagation loss in millimetre wave band [3]. The smart antenna could be an adaptive array or the switched-beam smart antenna (SBSA). SBSA uses beamforming network (BFN), radio frequency (RF) switches and an antenna array to enhance sensitivity in the direction with strongest received signal strength (RSS) as the target moves throughout the footprint [4]. It offers many of the advantages of the fully adaptive systems at less expense and complexity [5] and a satisfactory communication link was demonstrated at $28 \mathrm{GHz}$ frequency band $[6,7]$ in none line of sight (NLOS) environment with beamforming algorithm in an outdoor coverage.

\footnotetext{
* Corresponding author, tel: +234-803-581-2519
}

The implementation of Butler matrix (BM) is the key component of a switched-beam smart antenna due to several advantages including; ease of implementation, ability to generate orthogonal beams with narrow beamwidth, high directivity and absence of external control. The $4 \times 4$ BM BFN provides four output signals with equal power level and the progressive phase shift of $\pm 45^{\circ}$ and $\pm 135^{\circ}$ when excited at different ports. Therefore, by exciting any of the input ports switchedbeam capability can be achieved. In [8], travellingwave, slot antenna arrays based on a $4 \times 4$ BM with 4 $\times 4$ array antenna was proposed at $28 \mathrm{GHz}$. However, the authors did not consider the fact that a sudden $90^{\circ}$ bend in a microstrip will cause a notable portion of the signal on the strip to be reflected back, transmitting only part of the signal around the bend. Moreover, the series-fed slots printed on the ground layer serve as the radiator. Consequently, a low peak gain of $7 \mathrm{~dB}$ was achieved, which is too poor for communication at millimetre wave due to severe attenuation and path loss. Switched-beam antenna based on a $4 \times 4 \mathrm{BM}$ was demonstrated at $60 \mathrm{GHz}$, [9], but the short quarter wavelength electrical length separating the ports of BM at $60 \mathrm{GHz}$ was not considered. Thus, only 
one port was connected to the connector at a time for measurement.

To overcome these problems, this work presents a compact switched-beam array antenna based on $4 \times$ $4 \mathrm{BM}$ at $28 \mathrm{GHz}$. Series-fed microstrip patch array with short inter-element distance transmission lines are used to enhances antenna efficiency and a small portion of the diagonal between the inner and outer corners of the un-mitered bends on transmission lines are cut off to reduce reflection. Furthermore, input ports are extended to eliminate the ports proximity problem of [9] and realized a switched-beam antenna that is simple to integrate with other electronic components.

\section{BUTLER MATRIX DESIGN AND DISCUSSIONS}

The proposed BM is a structure that consists of hybrid couplers, crossovers and phase shifters. To ensure that the K-connectors are used in the component, the hybrid coupler has unequal input-output port separation to avoid the problem encountered in [9].

\subsection{Hybrid Coupler:}

Figure 1 depicts the proposed BLC used as the input port to the $4 \times 4 \mathrm{BM}$. One important aspect of the design of BLC at millimetre wave is selecting the material of the substrate. This is because when the frequency becomes higher, the wide line widths ( $W t)$ required by the low impedance lines may create an undesirable aspect ratio, due to the shortened quarter-wavelength sections. Therefore, it may be difficult to realize BLC in a single substrate of high thickness at millimetre wave, because the centre section $(S)$ will reach the lower limits of a practical realization. Thus, RT/duroïd5880 substrate with a dielectric constant of 2.2, a thickness of $0.254 \mathrm{~mm}$, and the nominal loss tangent of about 0.0009 is chosen. The low loss characteristic of the substrate is added advantage. Another challenge in designing planar BM at millimetre wave frequency is that the ports of BM are separated by $\lambda / 4$ electrical length. As a result, it is almost impossible to apply a planar design of BM with $\mathrm{K}$-connectors at millimetre wave frequency band due to the short distance between the ports. To overcome this, the proposed coupler is achieved by expanding the input ports of the designed coupler. The design is then optimized with Computer Simulation Technology (CST) Microwave Studio (MWS). Different dimensions of the designed coupler are detailed in Table 1.

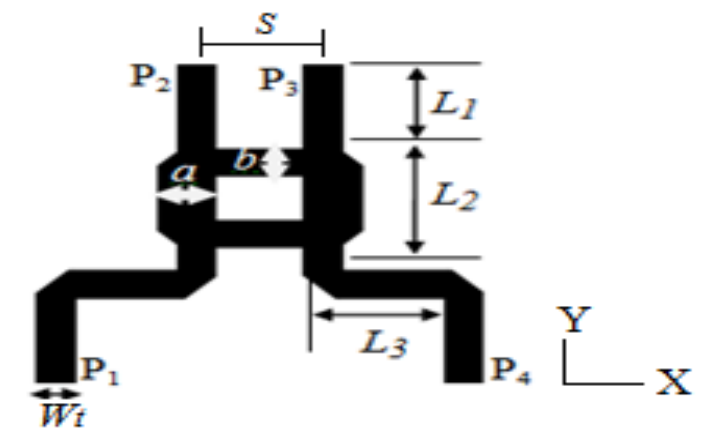

Figure 1: Proposed branch line coupler

Table 1: Material properties and dimensions of the

\begin{tabular}{cccccc}
\multicolumn{6}{c}{$B L C$} \\
$\mathrm{a}(\Omega)$ & $\mathrm{b}(\Omega)$ & $\begin{array}{c}\mathrm{Wt} \\
(\Omega)\end{array}$ & $\begin{array}{c}\mathrm{L} \\
(\mathrm{mm})\end{array}$ & $\begin{array}{c}\mathrm{L} 2 \\
(\mathrm{~mm})\end{array}$ & $\begin{array}{c}\mathrm{L} 3 \\
(\mathrm{~mm})\end{array}$ \\
\hline 32.5 & 47.2 & 50.8 & 11.8 & 5.87 & 5.25 \\
\hline
\end{tabular}

The hybrid coupler is designed to operate from $24 \mathrm{GHz}$ to $32 \mathrm{GHz}$. Figure 2 shows the simulated S-parameter of the proposed coupler. The reflection coefficient and isolation are $33.9 \mathrm{~dB}$ and $48.5 \mathrm{~dB}$, while the coupling and insertion losses are $-3.51 \mathrm{~dB}$ and $-3.08 \mathrm{~dB}$ at the designed frequency, respectively. The phase difference and amplitude imbalance of the proposed are plotted in Figure 3. From the graph, considering $90^{\circ} \pm 5^{\circ}$ output phase difference, the frequency range covers from $25.1 \mathrm{GHz}$ to $32 \mathrm{GHz}$ with $24.64 \%$ simulated fractional bandwidth. The amplitude imbalance is less than $1.09 \mathrm{~dB}$ across the band. The designed hybrid coupler is ensured to have almost equal power splitting, with high isolation and accurate $90^{\circ}$ phasing.

\subsection{Butler Matrix}

$\mathrm{BM}$ is an $\mathrm{N} \times \mathrm{N}$ multi-port network that has $\mathrm{N}$ number of inputs and $\mathrm{N}$ number of outputs. It consists of BLC, crossovers and phase shifters and divides the input signal into $\mathrm{N}$ signals of equal amplitude; with phase distribution across the output that is based on the order of the matrix. The design of 3-dB BLC is the most significant part in the design of the BM. This is because the insertion loss of 3-dB BLC determines how well the designed $B M$ matrix distributes the input signal among all the ports. After designing the BLC, the $0-d B$ crossover was achieved by a tandem connection of two BLCs. The crossover was designed with good matching and good isolation as the top priority for the input power to be fully transmitted to the output ports. Therefore the target was to achieve $0 \mathrm{~dB}$ and $0^{\circ}$ phase shift at the coupling port. 


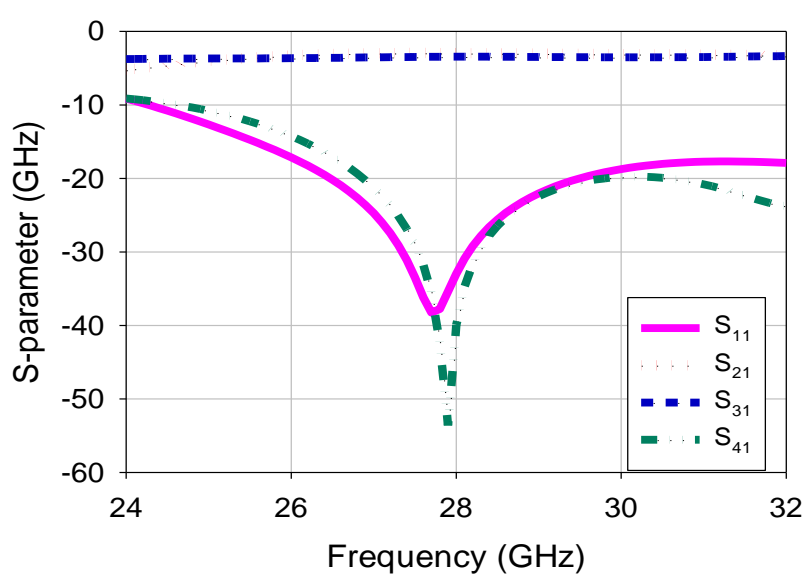

Figure 2: Simulated S-parameter of the proposed BLC

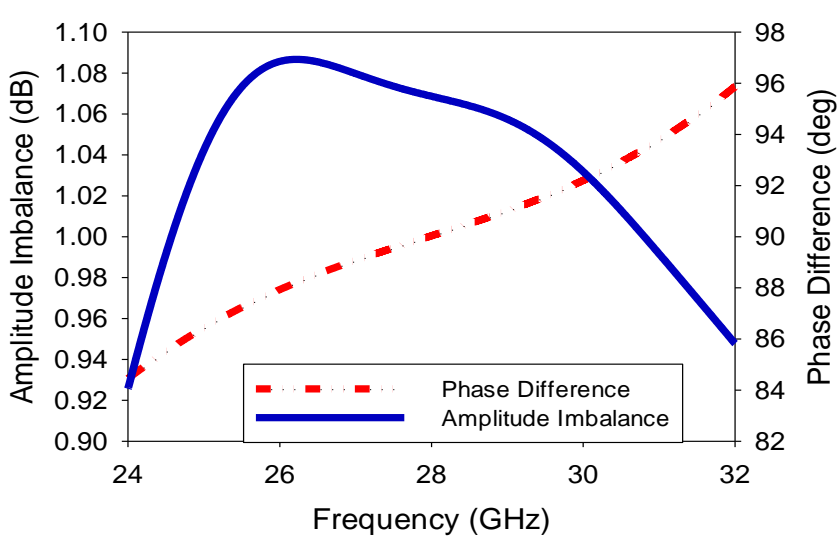

Figure 3: Comparison of the simulated phase difference and amplitude imbalance of the proposed $B L C$

Finally, the phase shifter was implemented with the transmission lines of lengths $\Delta l$ that will introduce the necessary phase shift. The phase shift $\Delta \varphi$ (deg), associated with a transmission line of length $l(\mathrm{~m})$ is given by Equation $1[10]$ :

$$
\Delta l=\Delta \varphi / \beta=\left(2 \pi / \lambda_{g}\right) \Delta \varphi
$$

According to Moody [11], the design principle of a $\mathrm{N}$ $\times \mathrm{N} B M$ can provide a progressive phase difference at the output with a phase increment given by:

$$
\text { Phase difference }= \pm(2 \mathrm{n}-1) / N * 180
$$

where $\mathrm{N}$ is the order of the matrix and $\mathrm{n}$ is the integer that varies from 1 to $N / 2$. Thus for a $4 \times 4 \mathrm{BM}$, the phase differences are $\pm 45^{\circ}$ at port $\mathrm{P} 1$ and port $\mathrm{P} 4$, and $\pm 135^{\circ}$ at port $\mathrm{P} 3$ and port $\mathrm{P} 2$, respectively.

The final geometry of the proposed $\mathrm{BM}$ is illustrated in Figure 4. Ports $\mathrm{P} 1, \mathrm{P} 2, \mathrm{P} 3$ and $\mathrm{P} 4$ are the input ports of the matrix. Ports P5 to P8 are the output ports used to feed the antenna array with inter-element separation (d) of half wavelength of the transmission line. Figure 5 and 6 illustrate the simulated return loss and transmission coefficients of the designed BM. From Figure 5, the return loss is better than $10 \mathrm{~dB}$ from $26.2 \mathrm{GHz}$ to $30.25 \mathrm{GHz}$ in all the input ports (due to symmetry only one port is shown).

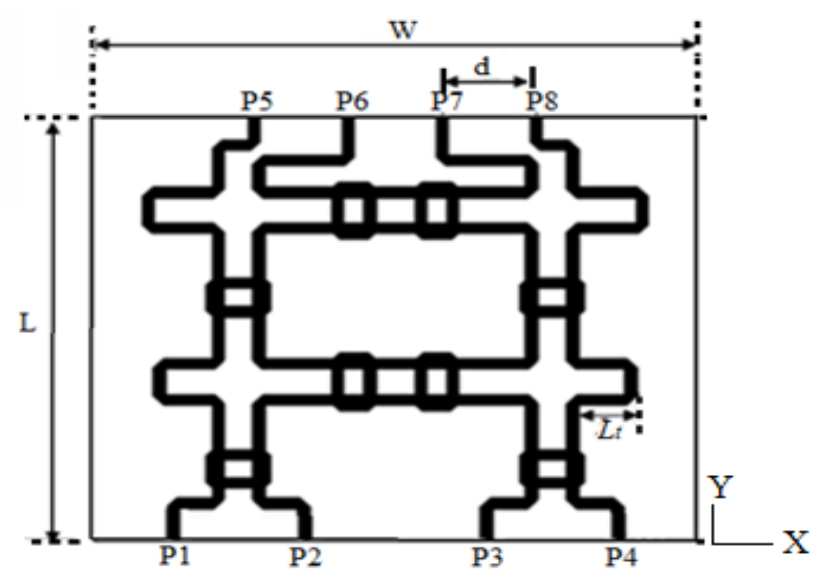

Figure 4: The proposed Butler matrix

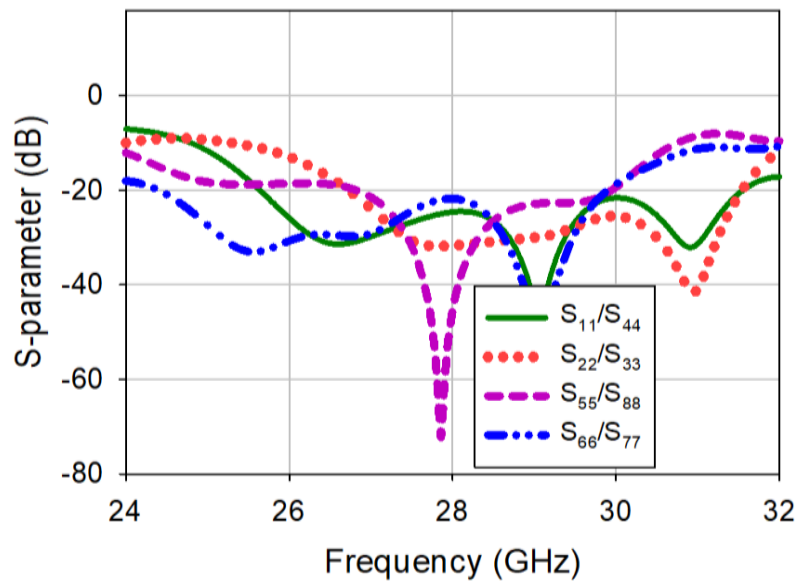

Figure 5: Simulated reflection coefficient of the Butler matrix

The average transmission coefficient from the input portsP1, P2, P3 and P4 to the output ports P5, P6, P7, and $P 8$ over the frequency range of 25 to $31 \mathrm{GHz}$ is $10.5 \mathrm{~dB}$ against the $6.02 \mathrm{~dB}$ theoretical value. This is due to the losses in all the individual components that make up the BM, especially the BLC with extended transmission lines. Figure 7 represents the coupling level of port $\mathrm{P} 1$ to the other input ports. The isolation coefficients between the ports are below $-20 \mathrm{~dB}$ at the design frequency.

\subsection{Antenna Design}

The layout of the proposed switched-beam antenna is shown in Figure 8 . It consists of a $4 \times 4$ BM integrated together with a $4 \times 4$ array antenna. 


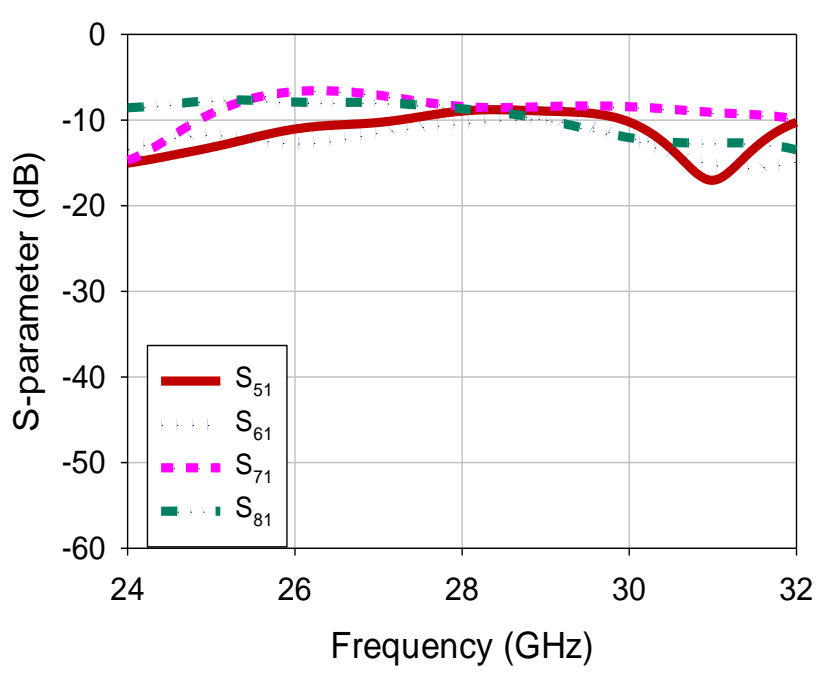

Figure 6: Simulated transmission coefficient of the Butler matrix

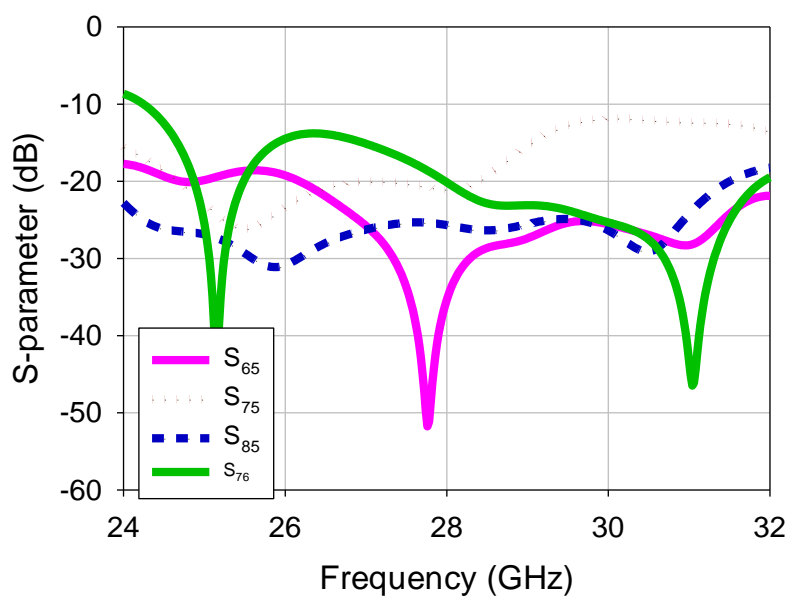

Figure 7: Simulated isolation between the ports of the Butler matrix

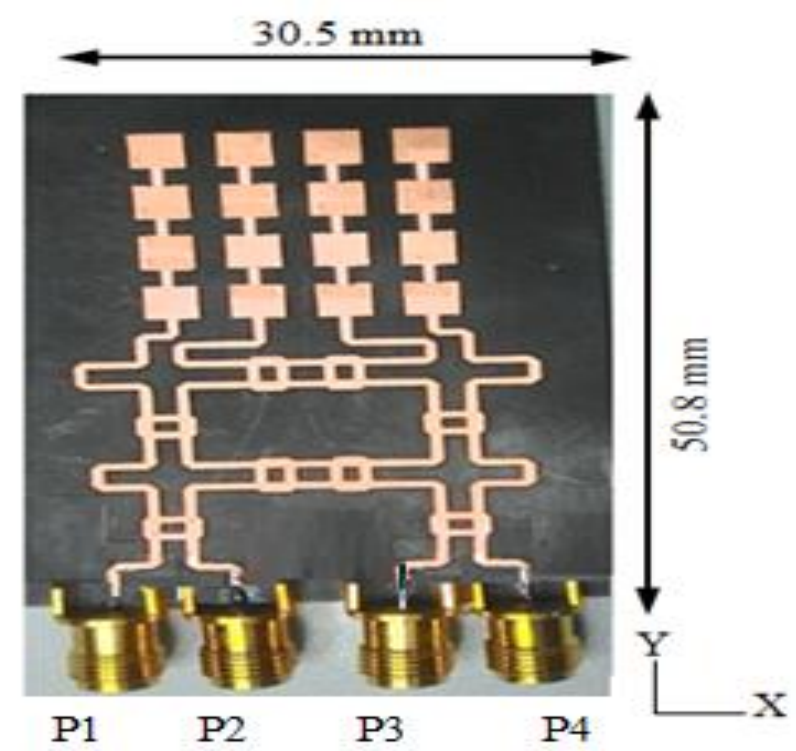

Figure 8: Layout of the fabricated switched-beam antenna

The design is done using Rogers RT/Durold 5880 substrate material of thickness $0.254 \mathrm{~mm}$ dielectric constant of 2.2 and loss tangent of 0.0009 to reduce surface wave excitation, improve radiation efficiency and to obtain a single layer with 50 -ohm input impedance. All the individual component parts of the BM starting from branch line coupler (BLC), phase shifter and the crossovers are designed separately and optimized to reduce phase errors and transmission losses at the designed frequency. Integrating BM with antenna array creates multiple beams which can produce fast discrete electronic switching of the antenna beam with an adaptive control unit. This characteristic enables the control of beam direction of an antenna when connected to the outputs of the BM. Figure 8 illustrates the prototype of the proposed antenna. It consists of a $4 \times 4$ BM and a $4 \times 4$ array antenna.

The measured reflection coefficient is compared to the simulated result in Figure 9. From the result, the measured $S_{11}$ and $S_{22}$ have good correlation with the simulated result, showing good impedance matching. The impedance bandwidth of $S_{11}$ and $S_{22}$ simulated are $23.9 \%(6.7 \mathrm{GHz})$ ranging from $24.8 \mathrm{GHz}$ to $30.4 \mathrm{GHz}$, $30.9 \mathrm{GHz}$ to $32 \mathrm{GHz}$ and $20 \%(5.6 \mathrm{GHz})$ that ranges from $26.4 \mathrm{GHz}$ to $32 \mathrm{GHz}$. However, when measured, there is little shift at both the upper and lower frequency of $S_{11}$ and at the lower frequency of $S_{22}$ reducing the bandwidth by less than $0.5 \mathrm{GHz}$. The deviation could be attributed to dry joint (the connector pin diameter is $0.76 \mathrm{~mm}$ against $0.25 \mathrm{~mm}$ thickness of the substrate), fabrication and measurement errors.

The radiation patterns corresponding to ports $\mathrm{P} 1$ to $\mathrm{P} 4$ are measured and found to agree well with simulations as can be seen in Figure 10. The radiation patterns are measured in an indoor anechoic chamber using a farfield measurement system at a resonant frequency of $28 \mathrm{GHz}$. The measured radiation pattern shown here are plotted and normalized to $0^{\circ}$.

Finally, the proposed antenna is compared with work done by A. T. Alreshaid [8] a travelling-wave slot antenna array using $4 \times 4 \mathrm{BM}$. This is chosen as a good measure for the performance of the proposed design because they used $4 \times 4 \mathrm{BM}$ to feed a $4 \times 4$ array antenna at the same $28 \mathrm{GHz}$ of frequency. From the report, only the gain of Port 1 and 2 were mentioned. Concerning the realized beam direction, it was only shown in a graph but clearly stated.

From Table 2, this work demonstrated better gain and size reduction compared to its counterpart. Maybe because they use slot antenna, their radiating area is small and their gain is so low. 


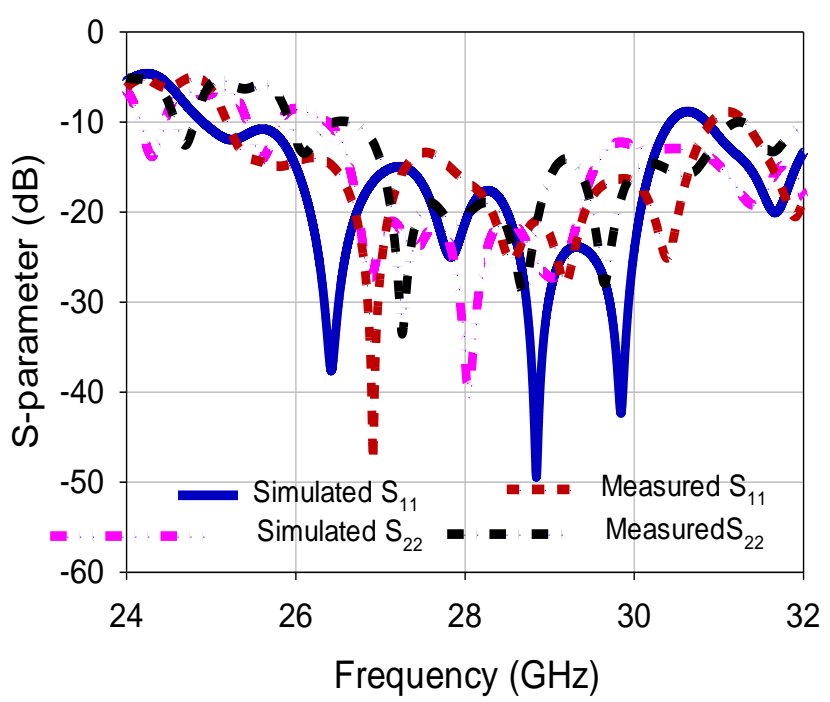

Figure 9: Comparison of the simulated and measured reflection coefficient of the proposed antenna

\section{CONCLUSION}

The realization of a compact low cost switched-beam array antenna at $28 \mathrm{GHz}$ has been demonstrated in a series-fed microstrip technology on BM BFN. The proposed antenna consists of a $4 \times 4 \mathrm{BM}$, integrated to $4 \times 4$ array antenna implemented on a single layer patch. The results obtained have shown that the design is able to produce four orthogonal beams pointing to $13.8^{\circ},-43.5^{\circ}, 44^{\circ}$ and $-14^{\circ}$, at $\mathrm{P} 1, \mathrm{P} 2, \mathrm{P} 3$ and $\mathrm{P} 4$ respectively. The radiation efficiency of the four ports is greater than $80 \%$ at the designed frequency. The peak gain of $15.9 \mathrm{dBi}$ and size of 30.5 $\times 50.8 \times 0.25 \mathrm{~mm}^{3}$ obtained in this work is far better than the peak gain of $7 \mathrm{~dB}$ and size of $53.7 \times 61.2 \times$ $0.13 \mathrm{~mm}^{3}$ realized in [8]. The proposed antennas have great potentials in $5 \mathrm{G}$ wireless communication system applications and capable of simple integration with other electronic components.

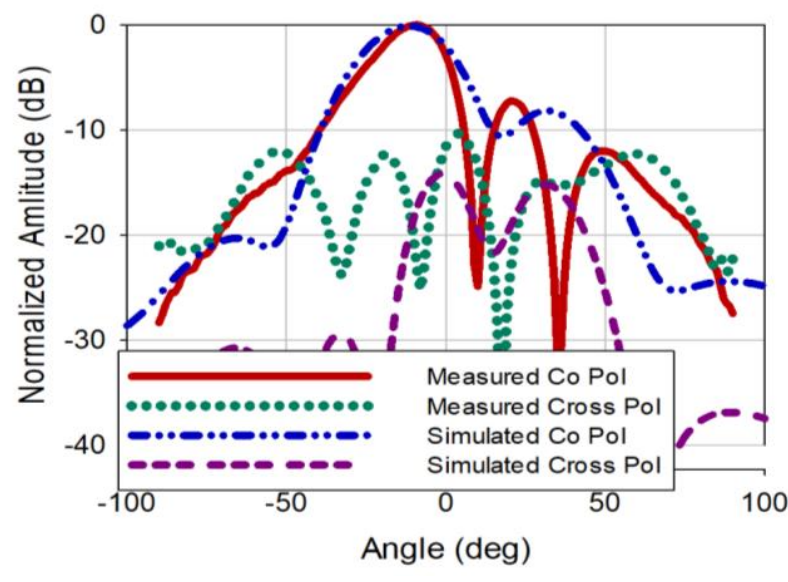

(b)

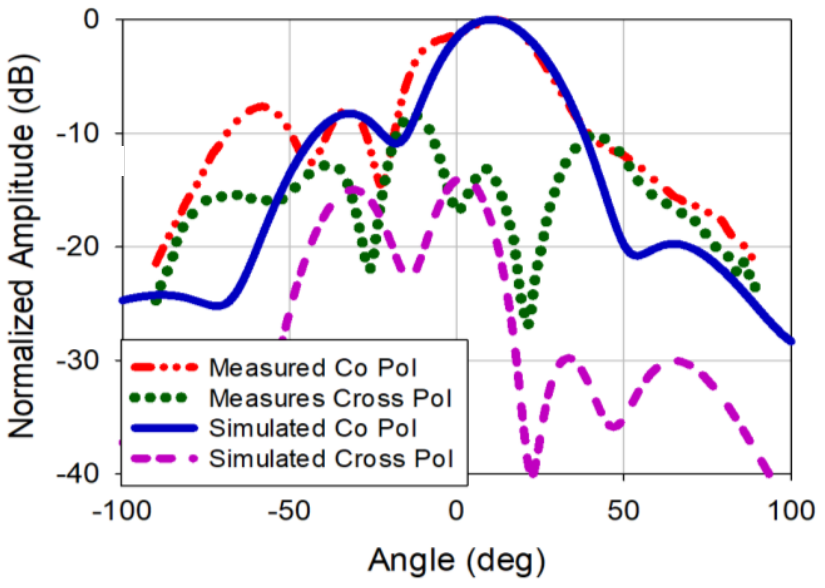

(a)

Figure 10: Simulated and measured radiation patterns of the antenna array fed by $4 \times 4$ Butler matrix (a) port 1 and (b) port 4

Table 2: Result Comparison with $4 \times 4 \mathrm{BM}$ at $28 \mathrm{GHz}$

\begin{tabular}{|c|c|c|c|c|c|}
\hline Reference & Ports & Port 1 & Port 2 & Port 3 & Port 4 \\
\hline \multirow{5}{*}{$\begin{array}{l}\text { Alreshaid, A. T. } \\
\text { Sharawi, M. S. } \\
\text { Podilchak, S. et } \\
\text { al[8] }\end{array}$} & Gain & $4.6 \mathrm{dBi}$ & $6.5 \mathrm{dBi}$ & - & - \\
\hline & Beam direction & - & - & - & - \\
\hline & $\begin{array}{l}\text { BM Size + } \\
\text { Antenna Size }\end{array}$ & \multicolumn{4}{|c|}{$53.7 \mathrm{~mm} \times 61.2 \mathrm{~mm} \times 0.13 \mathrm{~mm}$} \\
\hline & Antenna type & \multicolumn{4}{|c|}{ travelling-wave, slot antenna arrays } \\
\hline & Frequency & \multicolumn{4}{|l|}{$28 \mathrm{GHz}$} \\
\hline \multirow{5}{*}{ [This work] } & Gain & $15.9 \mathrm{~dB}$ & $12.9 \mathrm{~dB}$ & $13.0 \mathrm{~dB}$ & $15.8 \mathrm{~dB}$ \\
\hline & Beam direction & $13.8^{\circ}$ & $-43.5^{\circ}$ & $44.0^{\circ}$ & $-14.0^{\circ}$ \\
\hline & $\begin{array}{l}\text { BM size }+ \\
\text { Antenna Size }\end{array}$ & \multicolumn{4}{|c|}{$30.5 \mathrm{~mm} \times 50.81 \mathrm{~mm} \times 0.0175 \mathrm{~mm}$} \\
\hline & Antenna type & \multicolumn{4}{|c|}{ Microstrip series fed array antenna } \\
\hline & Frequency & \multicolumn{4}{|l|}{$28 \mathrm{GHz}$} \\
\hline
\end{tabular}




\section{REFERENCES}

[1] Roh, W. Seol, .J.-Y. Park, .J. Lee, et al 'Millimetrewave beamforming as an enabling technology for $5 \mathrm{G}$ cellular communications: theoretical feasibility and prototype results", IEEE Communications Magazine, vol. 52, No. 2, pp. 106-113, February 2014

[2] Sun, S. MacCartney, .G.R. Samimi et al "Millimetre wave multi-beam antenna combining for 5G cellular link improvement in New York City", IEEE International Conference on Communications (ICC), pp 5468-5473, 2014

[3] "Samsung Tomorrow Samsung Announces World's First $5 \mathrm{G}$ mmWave Mobile Technology". http://global.samsungtomorrow.com/samsungannounces-worlds-first-5g-mmwave-mobiletechnology/.. Accessed on May 13, 2013

[4] Denton, .S. Zavidniak, .P. and Hodgkiss, .W. "High altitude airborne cellular base stations antenna analysis", IEEE Aerospace and Electronic Systems Magazine, vol 4, No. 25 pp 30-36, 2010.

[5] Rahim, M. K. A. Salleh, M. N. M. Ayop, .O. et al "Switched-beam antenna system design", Proceedings of the IEEE RF and Microwave Conference, pp 302-305, 2008.

[6] Roh, .W. Seol, .J.-Y. Park, .J. Lee, .B. Lee, .J. Kim, .Y. Cho, .J. Cheun, .K. and Aryanfar, .F. "Millimetre-wave beamforming as an enabling technology for $5 G$ cellular communications: theoretical feasibility and prototype results", IEEE Communications Magazine, vol 2, No. 52 pp 106-113, 2014.

[7] Rappaport, .T. S. Gutierrez, .F. Ben-Dor, .E. Murdock, .J. N. Qiao, .Y. and Tamir, .J. I. "Broadband millimetre-wave propagation measurements and models using adaptivebeam antennas for outdoor urban cellular communications", IEEE Transactions on Antennas and Propagation, vol 4, No 61, pp 1850-1859,2013.

[8] Alreshaid, .A.T. Sharawi, .M.S. Podilchak, S. et al. "Compact millimetre-wave switched-beam antenna arrays for short range communications". Microwave and Optical Technology Letters, vol 8, No 58, pp.1917-1921, 2016.

[9] Tseng, .C.H. Chen, .C.J. and Chu, .T.H. "A lowcost $60-\mathrm{GHz}$ switched-beam patch antenna array with Butler matrix network", IEEE Antennas and Wireless Propagation Letters, vol 7, pp.432-435.

[10]Im, .Y.T. Lee, .J.H. Jeong, .Y.W. et al "A beamswitchable coupled feeding network in X-band", Microwave and Optical Technology Letters, vol 8, No 52, pp.1865-1868.

[11]Moody, .H. "The systematic design of the Butler matrix", IEEE Transactions on Antennas and Propagation, vol 6, No 12, pp 786-788. 1964. 